\title{
Measuring Digital and Traditional Financial Inclusion in Egypt: A New Index
}

\author{
Doaa Mohamed Ismael* and Samar Salah Ali \\ Faculty of Commerce and Business Administration, Future University, Egypt
}

\begin{tabular}{l} 
ARTICLE INFO \\
\hline Keywords: \\
Fintech \\
Digital Finance \\
Multi - Dimensional Index \\
Principle Component \\
$\quad$ Analysis
\end{tabular}

\section{Introduction}

Financial inclusion, defined as the ease of access to and usage of formal financial services by all people in the economy, is one of the most important topics on the global policy agenda for sustainable development. More specifically, low level of financial inclusion hinders economic growth and hence sustainable development. Accordingly, financial inclusion is seen as one of the main cornerstones of sustainable development since an inclusive financial system creates a base for inclusive long term economic growth, creates more jobs, helps small businesses to raise funds, maintain financial and social stability and achieve other national goals (Burgess

\footnotetext{
*Corresponding author E-mail address: doaa.ismael@fue.edu.eg Applied Research in Management and Economics, 4(2), 13-34. https://doi.org/10.33422/ijarme.v4i2.629
} 
and Pande, 2005; Beck et al. 2007; Soejachmoen, 2016). Therefore; promoting greater financial inclusion is seen as one of the main challenges that developing countries have to meet urgently since more than $90 \%$ of the unbanked people who lack the access to and usage of formal financial services are located in developing countries (Demirguc - kunt et al., 2018). Hence, financial inclusion is not only important, but it is set as a primary objective for all developing countries.

Egypt is not an exception, where the Egyptian government has launched the Sustainable Development Strategy (SDS): Egypt's Vision 2030, setting financial inclusion not only as a top national priority but as the main primary objective for the overall sustainable development strategy (Central Bank for Egypt, 2018). However, like any developing country, achieving high levels of financial inclusion is not an easy goal. According to the World Bank`s Global Findex database, as of 2017, only 33\% of the adult population in Egypt has a bank account which is much lower compared to other developing countries. Barriers perceived by the unbanked people have set insufficient funds to open a bank account, distance, too expensive to open a bank account, lack important official documentation, as the main barriers that prevent them from accessing and using formal financial services.

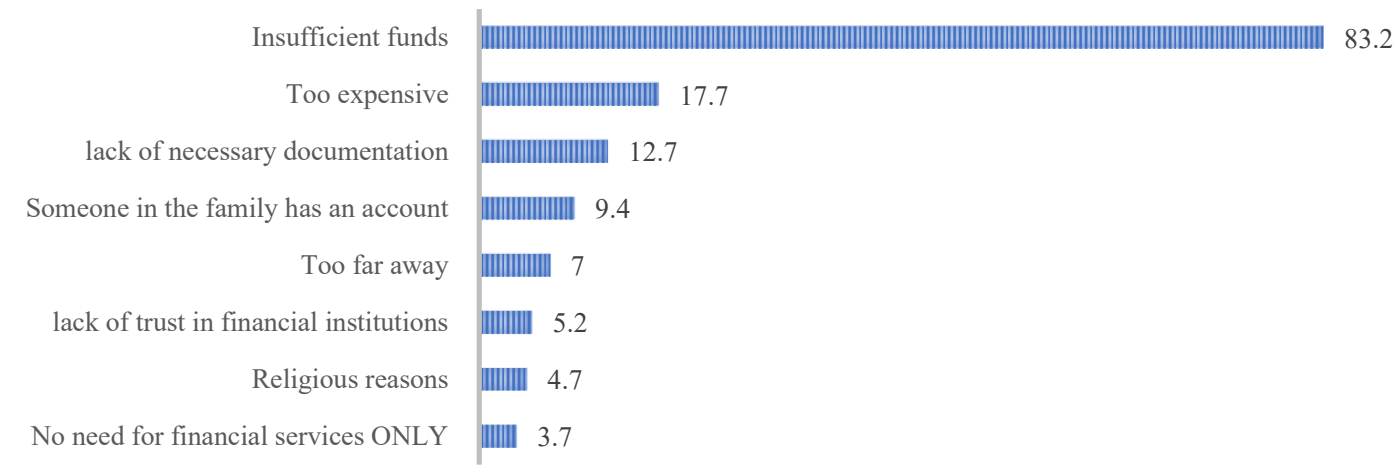

Figure 1. Barriers perceived by Egypt's unbanked population in 2017

Source. Global Findex Database, 2020

Digital finance can potentially engage unbanked people who are involuntary excluded from accessing and using formal financial services and hence achieving greater financial inclusion (Sun, 2018; and Ozili, 2018). Thus, rapid developments to digital platforms, e - money, QR code, and e - wallets are set as the roadmap for greater financial inclusion (Central Bank for Egypt, 2018). In this context, the inter - linkages between traditional financial inclusion, digital finance, and sustainable development requires an appropriate measure of financial inclusion. However, researchers are far from reaching a formal consensus where literature still lacks a comprehensive multidimensional index that can provide a complete and informative index (Park and Mercado Jr, 2018).

Although few studies took the attempt to measure the inclusiveness of the financial system; however, no study did quantify the financial inclusion of Egypt. This study aims to fill in this gap. This paper contributes to the literature by being the first to construct a novel comprehensive financial inclusion index using a three - stage principle component analysis (PCA). By doing so, we build two separate indices: one index for traditional financial inclusion by combining access, usage, and barriers indicators and one index for digital financial by combining access and usage indicators. Thus, our contribution is not limited to construct a financial inclusion index for Egypt, but we are the first to quantify separately a digital financial inclusion index for Egypt. By creating a separate index for traditional and digital financial inclusion, we were able to identify barriers hindering greater financial inclusion in Egypt, 
present which dimensions are the most important in defining financial inclusion, and finally analyze how digital finance can potentially lead to greater financial inclusion in Egypt.

The remainder of this paper is structured as follows. Section 2 review the literature. Section 3 discusses the data and methodology. Subsequently, we report our results and discussion in Section 4. Finally, Section 5 provides conclusion and policy recommendations.

\section{Literature Review}

\subsection{Definition of Financial Inclusion}

Financial inclusion is a broad concept that has been defined from different perspectives and dimensions depending on the country stage of development (Kempson and Whyley, 1999; Aduda and Kalunda, 2012; Damodaran, 2013; Sarma, 2016; Akileng et al., 2018; Awad and Eid, 2018). Although there is no one global definition for financial inclusion, its generally understood that financial inclusion is the process of insuring the access to and use of different formal financial services to be used by those vulnerable disadvantaged and low income groups in an adequate time and affordable cost (Damodaran, 2013, Kelly \& Rhyne, 2015; Sahay et al. 2015b, World Bank, 2014, Demirguc-kunt \& Levine, 2007; Bruhn \& love, 2014). In particular, an inclusive financial system means that financial services such as bank accounts, loans, savings, credit and insurance are easily accessible by all people and effectively used by them to meet their financial needs (Klapper \& Hess, 2016; Camara; Tuesta, 2015; World Bank 2018).

Although, formal financial institutions provide well diversified financial products; however, large percentage of adults till now still lack the access and usage of these financial services (Beck et al. 2007; Damodran, 2013; Camera \& Tuesta, 2014; Sahay et al., 2020; Ozili, 2018; Sun, 2018). Thus, financial exclusion is considered one of the main weakness of the traditional formal financial institutions. According to Devlin (2005) financial exclusion is defined as the inability to access or use formal financial services. Sinclair (2001) list distance, prices of financial products, and negative perception as the main reasons for financial exclusion. More recently, the World Bank (2014) identifies two types of financial exclusion; voluntary exclusion and involuntary exclusion. Voluntary exclusion refers to the group of people or firms who choose not to use formal financial services, either because they do not need those services or because of other cultural or religious reasons. From a macroeconomic point of view, voluntary exclusion is due to lack of demand. Whereas involuntary exclusion refers to some individuals or firms that may be involuntarily excluded from the financial system because of their insufficient income or they have an excessive lending risk profile (Amidži et al., 2004).

Digital finance can potentially overcome these problems that traditional approach has long been unable to deal with, reaching those involuntary excluded groups, and hence increase financial inclusion especially in the developing economies (Sun, 2018; Ozili, 2018; United Nations, 2016). Digital Finance deliver financial services through a reliable digital payment system, using mobile phones, computers or the internet that are faster, more efficient, and cheaper than traditional financial services (Manyika, 2016; Ozili; 2018). Hence digital finance increase financial inclusion through reaching the poor-underserved population, lower-income households and small- and medium enterprises (SMEs) (World Bank, 2014) and also by providing new financial products delivered by Fintech companies (Gomber, Koch and Siering, 2017).

The theoretical underpinning of the relation between digital finance and financial inclusion is based on the assumption that those who are excluded from accessing and using traditional financial services have or own a mobile phone with mobile internet data; thus the provision of financial services through mobile phones can increase the access to traditional financial services by those excluded people and hence digital finance can potentially lead to greater financial inclusion (Ozili, 2018). Accordingly, digital financial inclusion (DFI) can be defined as "digital access to and use of formal financial services by the excluded and underserved population" (CGAP, 2015 and Lyman 
\& Lauer, 2015). More specifically, it's about accessing and using the same traditional bank based financial services through digital channels without the need for direct interactions.

Against this background; financial inclusion cannot be simply defined as the use of formal financial services, an inclusive financial system is the one that is easily accessed, its services are effectively utilized, and minimize involuntary financial exclusion through the use of digital finance. Therefore, this paper uses Camara and Tuesta (2017) definition of financial inclusion where they view financial inclusion as a multidimensional concept. Accordingly, financial inclusion is "the one that maximizes usage and access while minimizes involuntary financial inclusion".

\subsection{Measurements of Financial Inclusion}

Although measuring the degree of financial inclusion (FI) is set on the top priorities of governments, researches, and policy makers, there is no consensus on how financial inclusion should be measured. Accordingly, existing literature proposed various methods to measure the degree of inclusiveness of any financial system (Park and Mercado Jr, 2015). Earlier studies measured only the extent through which the financial system is comprehensive using single indicators, either by assessing types of bank services provided or the proportion of the adults who have the access to these services through bank account. Thus, new variables were designed capturing deposits, loans and payments besides saving and borrowing of adults. These indicators are aggregated under two dimensions; access and usage of formal financial services (Beck et al, 2007; Honohan, 2008; Demirguc-Kunt and Klapper, 2012; Demirguc-Kunt et al, 2015, 2018).

However, FI is a multidimensional concept that cannot be accurately captured by single indicators, such as bank account ratios, number of automated teller machines (ATMs), credits and bank deposits (Sarma, 2016; Nguyen, 2020 and Camara \& Tuesta, 2014). Since when used alone, partial and incomplete information about the degree of comprehensiveness of the financial system is only provided. For this reason, different studies were conducted to find an appropriate measurement that can assess in a comprehensive way the extent through which formal financial services are accessed and used by adult population. Such measurement is called financial inclusion index. Sarma, (2008) was the first to provide a comprehensive measure of financial inclusion that incorporate information about the inclusiveness of the financial system from different dimensions in one single index. Accordingly, subsequent studies measure financial inclusion in a more comprehensive and multidimensional way. Gupte et al., (2012) measure degree of financial inclusiveness in India based on four dimensions; outreach, usage, ease of transactions, and cost of transactions. Sarma (2008, 2012, 2015) measures financial inclusion based on three dimensions; penetration, availability, and usage. Similarly, Park and Mercado $(2015,2018)$ build a multidimensional financial inclusion index based on several aspects such as bank branches, ATMs, domestic credit to GDP, borrowers and depositors.

All these studies (e.g. Huang and Zhang, 2020; Sethi and Sethy, 2019; Prastowo and Putriani, 2019; Goel and Sharma, 2017; Anwar et al., 2017; Park and Mercado, 2015; Yorulmaz, 2013; Gupte et al., 2012) use the same multidimensional approach proposed by Sarma, (2008) in measuring financial inclusion, since they found it more convenient to use such approach as it is similar to the methodology used by UNDP in calculating well known indices such as, human development index (HDI) and human poverty index (HPI). Although these studies provide better measurement to the FI index, however; a major weakness in all these studies is that the weights of each dimension are set arbitrary based on the researcher and thus all dimensions are assumed to have the same effect on FI. Therefore, the contribution of Amidzic et al; (2014) is considered a turning point in this field where they construct a composite FI index using factor 
analysis method (FA) that assign weights to each proposed dimension rather than assuming equal weights.

Camera \& Tuesta $(2014 ; 2017)$ made another important contribution to the literature. They were the first to measure FI considering both demand - and - supply side information through adding barriers as an important dimension while constructing their FI index. Moreover, similar to Amidzic et al., (2014) they used a two - stage Principle Component Analysis (PCA) method to estimate the weights for each dimension to avoid drawback of Sarma methodology of arbitrary weights. However, one major criticism to this approach is that using FA or PCA reduce the number of variables to smaller set of factors and hence the financial inclusion index is incomplete and partially informative.

Meanwhile, with the growing interest of governments, policymakers, and researchers, the IMF has constructed a novel composite FI index. The proposed approach depends on three - stage PCA where they construct two separate indices; traditional bank based and digital financial inclusion index. They proposed a new digital financial inclusion index to measure the extent through which digital finance can potentially lead to greater financial inclusion (Sahay et al., 2020). Although the novel index proposed by Sahay et al., 2020 provide a better measurement of the degree of inclusiveness of the formal financial system, however, their proposed financial inclusion index not only fail to provide a clear picture about the barriers that prevent people from using and accessing traditional bank - based financial services, but it also did not tell how digital finance can close this gap.

The review of the literature shows that each proposed developmental approach used in measuring financial inclusion index has its own advantages and drawbacks. It was evident that the measurement of financial inclusion index among all empirical studies are either different in the methodology used or in the dimensions define financial inclusion. Thus, the measurement of the degree of FI has not yet reached a formal consensus (Park and Mercado, 2015; Mialou et al., 2017). More Specifically, literature still lacks a comprehensive multidimensional index that can provide a complete and informative picture. In addition; in measuring financial inclusion, variables such as: online purchases, online utility payments, and mobile money were neglected and thus the role of digital finance in achieving greater financial inclusion was absent. Our study aims to fill in this gap.

\section{Methodology}

\subsection{Data sources and Dimensions:}

Measuring the degree of financial inclusion is still controversial issue. To date measurements of financial inclusion were done by using only supply side aggregate date - such as number of ATMs and bank branches (e.g. Amidzic et al. (2014); Honohan (2008), Chakravarty and Pal (2013); and Samra $(2008,2012))$. However, the way supply side data is gathered provides incomplete information about the inclusiveness of the financial system since it does not encounter for the barriers perceived by those people who are involuntary excluded from using or accessing formal financial services. Thus, additional information from demand side should be used when it comes to usages (Camera \& Tuesta, 2017).

In brief, previous attempts to measure financial inclusion are either incomplete in terms of information since it lacks information on financial exclusion or subject to methodological problems (Camera \& Tuesta, 2014). Moreover, from literature review its clear that measurements of financial inclusion index did not incorporate information about digital finance - an important dimension in defining financial inclusion. Therefore, we combine variables on "access", "usage" and "barriers" for the traditional index during the period 2004-2019 and only "access" and "usage" for the digital index. The summary of measurement variables and data sources are presented in table 1 


\section{- Access}

An inclusive financial system requires that formal financial services are easily accessed or reachable by people. According to Sarma (2016) any financial system is penetrated widely among society if the bank transaction points are easily accessed. Therefore, we use two indicators to measure the accessibility of traditional financial services; the Number of ATMs per 100,000 adults and Number of branches per 100,000 adults. On the other hand, digital financial inclusion indicates people access to their bank accounts through the internet or mobile phones. Therefore, to assess the extent through which people can access formal financial services through digital channels three indicators were used Mobile cellular subscription per 100 people, \% of mobile internet users and Number of registered mobile money accounts. The first two indicators are used as a proxy to digital infrastructure which is essential for digital access to traditional financial services. According to the World Bank (2017) mobile phones can potentially open access to mobile money accounts and thus overcome the need to travel long distance to a bank. While internet is seen as a mean of digital payments, paying bills, or make an online purchase. The third indicator is added based on the suggestion of Sarma (2016). Due to the rapid growth of fintech companies' mobile money accounts are said to unlock access to traditional financial services by providing digital identity for unbanked population and thus allowing previously excluded people to access traditional bank services through their mobiles (GSMA, 2016; Donovan, 2012).

\section{- Usage}

Although access to formal financial services is the primary dimension that define financial inclusion, however; an inclusive financial system is the one in which financial services are easily accessed, used and utilized (Sarma, 2016). According to Kempson et al; (2004) many people make margin use to their bank account either because bank branches are remotely located, or they have bad experience with the financial service provider. Thus, having access to formal financial services is not enough for financial system to be inclusive, people must utilize these services. The utilization of traditional bank services can take different forms such as; credit, deposits, and payments. Therefore, we use four indicators to build usage dimension as proposed by Beck et al. (2007); Gupte et al. (2012); Lenka and Bairwa (2016) and Sarma (2016), Nguyen (2020) Number of deposit accounts with commercial banks per 1,000 adults and Number of borrowers from commercial banks per 1,000 adults. In addition, to ensure that traditional financial services are fully utilized, we took two additional indicators; Number of debit cards per 1,000 adults and Number of credit cards per 1,000 adults. On the other hand, although mobile phones or the internet are an alternative to debit and credit cards for making direct payments from an account. However, most people still pay in cash. Thus, owning a smart phone and have mobile data internet is not a reliable measure for digital access, it's how financial services are utilized digitally should be considered. According to the World Bank digital payments are in rise whether to make an online purchase, pay for a bill, or make any kind of mobile money transactions. We use four indicators to build this dimension Mobile payments accounts, No. of mobile money transactions per 1000 adults, makes online purchases or pay an online bill and Made an online purchase via a mobile.

\section{- Barriers}

Globally, around 1.7 billion people are unbanked. Therefore, barriers must be considered when measuring FI to construct a comprehensive index. Barriers perceived by unbanked individuals explaining why some people are involuntary excluded from accessing and using the traditional formal bank services which is essential to assess the extent of financial inclusion. The world bank in the Global Findex dataset has cited barriers such as distance, lack of documentations, and lack of enough money as the most important barriers. However, due to data limitation for 
Egypt we were unable to use this dataset, instead we used other four indicators to build this dimension based on Ministry of Communication and Information Technology. The two indicators number of commercial bank branches per $1000 \mathrm{~km}^{2}$ and number of ATMs per 1000 $\mathrm{km}^{2}$ were used as a proxy for distance. While saved at financial institutions rural aged $15+$ and borrowed from a financial institution in rural areas were used as a proxy for lack of sufficient funds and lack of documentations, respectively.

Table 1.

Summary of variables and data sources used in the model

\begin{tabular}{|c|c|c|c|}
\hline Traditional Financial inclusion Index & Source & Digital Financial Inclusion Index & Source \\
\hline $\begin{array}{l}\text { Access } \\
\text { No. of ATMs per } 100,000 \text { adults. } \\
\text { No. of branches per } 100,000 \text { adults. }\end{array}$ & FAS- IMF & $\begin{array}{l}\text { Access } \\
\text { Mobile cellular subscription per } \\
100 \text { people. } \\
\text { Number of registered mobile } \\
\text { money accounts. } \\
\% \text { of mobile internet users. }\end{array}$ & $\begin{array}{l}\text { ITU } \\
\text { FAS- IMF } \\
\text { ITU }\end{array}$ \\
\hline $\begin{array}{l}\text { Usage } \\
\text { No. of deposit accounts with commercial } \\
\text { banks per } 1,000 \text { adults. } \\
\text { No. of borrowers from commercial banks } \\
\text { per } 1,000 \text { adults. } \\
\text { No. of debit cards per } 1,000 \text { adults. } \\
\text { No. of credit cards per } 1,000 \text { adults. }\end{array}$ & FAS- IMF & $\begin{array}{l}\text { Usage } \\
\text { Mobile payments accounts. } \\
\text { No. of mobile money transactions } \\
\text { per } 1000 \text { adults. } \\
\text { Makes online purchases or pay an } \\
\text { online bill. } \\
\text { Made an online purchase via a } \\
\text { mobile. }\end{array}$ & MCIT \\
\hline $\begin{array}{l}\text { Barriers } \\
\text { No. of commercial bank branches per } \\
1000 \mathbf{k m}^{2} \text {. } \\
\text { No. of ATMs per } 1000 \mathbf{k m}^{2} \text {. } \\
\text { Borrowed from a FI in rural areas } \\
\text { Saved at FI rural aged } 15+\end{array}$ & $\begin{array}{l}\text { FAS- IMF } \\
\text { FAS- IMF } \\
\text { WB Findex } \\
\text { WB Findex }\end{array}$ & & \\
\hline
\end{tabular}

\section{Source. The author}

\section{- Index Construction}

This paper follows the approach proposed by Sahay et al., (2020). Accordingly, we construct a composite multidimensional financial inclusion index for Egypt, composed of both traditional bank based and digital financial inclusion index. Dividing the overall financial inclusion index into two indices give disaggregated information on the inclusiveness of the financial system, which helps policymakers in directing their efforts to the areas that need improvement. Although, PCA is biased towards the weights of the indicators, however, using three - stage PCA helps in overcoming this pitfall. Since each sub - index is defined by a set of highly correlated indicators, estimating the sub - indices first rather than estimating the overall index in one stage with all the indicators at one time, is a preferable strategy.

The first stage PCA: we combine indicators of "access", "usage" and "barriers" that define the dimensions or sub - indices used to build traditional financial inclusion index. Unlike Sahay et al., (2020), we add a third dimension to its measurement which is "barriers" to capture those who are excluded from using the formal financial service and hence provide more comprehensive picture. On the other hand, indicators of "access" and "usage" that define the dimensions were combined to construct digital financial inclusion index. That is, for each index the three endogenous variables $\mathrm{Y}^{\mathrm{u}}, \mathrm{Y}^{\mathrm{a}}, \mathrm{Y}^{\mathrm{b}}$ are unobserved and so they must be estimated with their corresponding parameters $(\beta, \varphi, \alpha)$ in the following equation system:

The dimensions of "usage", "access" and "barriers" of the traditional financial inclusion index are computed by the following equation system:

$$
\mathrm{Y}^{\mathrm{a}}=\beta_{1} \mathrm{ATMs}+\beta_{2} \text { bank branches }
$$




$$
\begin{aligned}
& \mathrm{Y}^{\mathrm{u}}=\alpha_{1} \text { credit cards }+\alpha_{2} \text { debit cards }+\alpha_{3} \text { deposits accounts }+\alpha_{4} \text { Loans } \\
& \mathrm{Y}^{\mathrm{b}}=\varphi_{1} \text { branches } \mathrm{km}_{2}+\varphi_{2} \mathrm{ATM} \mathrm{km}_{2}+\varphi_{3} \text { savings }+\varphi_{4} \text { borrowings }
\end{aligned}
$$

The dimensions of "usage", and "access" of the Digital financial inclusion index are computed by the following equation system:

$\mathrm{Y}^{\mathrm{a}}=\beta_{1}$ mobile subscriptions $+\beta_{3}$ mobile money accounts $+\beta_{4}$ mobile internet users

$\mathrm{Y}^{\mathrm{u}}=\alpha_{1}$ Mobile payments accounts $+\alpha_{2}$ Mobile money transactions $+\alpha_{3}$ online payments $+\alpha_{4}$

$$
\text { Mobile online payments }
$$

For each index, we first find the scores of all the principal components of each of the three dimensions, since the principal components of each dimension are the linear combination of their respective input indicators, as follows:

$$
P C_{k}=\sum \dot{\eta}_{k p} X_{p}
$$

In Equation (6), $\eta_{k p}$ is the loading of each component or the correlation coefficient between the $k$-th principle component and the number of $p$ indicator or sub - indices. Then each dimension score is calculated as the weighted average of the respective PC, as follows:

$$
\begin{aligned}
D s_{t}^{a} & =\frac{\sum_{j, k=1}^{4} \lambda_{j}^{a} P C_{k t}^{a}}{\sum_{j, k=1}^{4} \lambda_{j}^{a}} \\
D s_{t}^{u} & =\frac{\sum_{j, k=1}^{4} \lambda_{j}^{u} P C_{k t}^{u}}{\Sigma_{j, k=1}^{4} \lambda_{j}^{u}} \\
D s_{t}^{b} & =\frac{\sum_{j, k=1}^{4} \lambda_{j}^{b} P C_{k t}^{b}}{\Sigma_{j, k=1}^{4} \lambda_{j}^{b}}
\end{aligned}
$$

where $D s_{t}$ represents the scores of the three dimension "access", "usage", and "barriers" for the $t^{\text {th }}$ observation; $\lambda \mathrm{j}(\mathrm{j}=1, \ldots, \mathrm{p})$ defined as the $j$-th eigenvalue of each of the three dimension, subscript $\mathrm{j}$ refers to the number of principal components that also equal to the number of indicators or sub-indices, $\mathrm{p}$. Finally, $P C_{k t}$ is the score of each dimension for the $t^{\text {th }}$ observation. Assuming that $\lambda 1>\lambda 2>\cdots>\lambda j$, where $\lambda \mathrm{j}$ represents the variance of the kth PC, which means that the largest variation in each dimension is captured by the first PC and so on. In brief, the first PC explain the largest information from the initial data. Since the main objective of our paper is to construct an index that is complete and informative such that it captures all the information from all individual indicators used in each dimension, rather than reducing the data dimensionality that will affect our index, the above equations are used.

The Second Stage PCA: it combines the sub - indices from the first stage PCA to compute a separate index for overall traditional $\left(\mathrm{FI}_{\mathrm{T}}\right)$ and digital financial inclusion index $\left(\mathrm{FI}_{\mathrm{D}}\right)$.

$$
\begin{aligned}
& \mathrm{FI}_{\mathrm{T}}=\omega \mathrm{Y}^{\mathrm{a}}+\omega \mathrm{Y}^{\mathrm{u}}+\omega \mathrm{Y}^{\mathrm{b}}+\varepsilon \\
& \mathrm{FI}_{\mathrm{D}}=v^{\prime} \mathrm{Y}^{\mathrm{a}}+v^{\prime} \mathrm{Y}^{\mathrm{u}}+\varepsilon
\end{aligned}
$$

The two indices $\left(\mathrm{FI}_{\mathrm{T}}, \mathrm{FI}_{\mathrm{D}}\right)$ is computed by replicating the same procedures as in the first stage PCA, thus each principle component is a linear component of the three sub - indices as follows:

$$
\begin{aligned}
& P_{1 i}=\varphi_{11} \lambda_{i}^{a}+\varphi_{12} \lambda_{i}^{u}+\varphi_{13} \lambda_{i}^{b} \\
& P_{2 i}=\varphi_{21} \lambda_{i}^{a}+\varphi_{22} \lambda_{i}^{u}+\varphi_{23} \lambda_{i}^{b} \\
& P_{3 i}=\varphi_{31} \lambda_{i}^{a}+\varphi_{32} \lambda_{i}^{u}+\varphi_{33} \lambda_{i}^{b}
\end{aligned}
$$


The third stage PCA: applying the same procedures of PCA on the two indices; traditional and digital financial inclusion indices, the following estimator for overall financial inclusion index is produced.

$$
F I_{i}=\frac{\sum_{j, k=1}^{p} \lambda_{j} P_{k i}}{\sum_{j, k=1}^{p} \lambda_{i}}
$$

So, the financial inclusion index is expressed as:

Or,

$$
F I_{i}=\frac{\sum_{j=1}^{3} \lambda_{j}\left(\varphi_{j 1} \lambda_{i}^{a}+\varphi_{j 2} \lambda_{i}^{u}+\varphi_{j 3} \lambda_{i}^{b}\right)}{\sum_{j=1}^{3} \lambda_{j}}
$$

$$
\mathrm{FI}_{\mathrm{i}}=\omega_{1}\left(\mathrm{FI}_{\mathrm{T}}\right)+\omega_{2}\left(\mathrm{FI}_{\mathrm{D}}\right)+\varepsilon
$$

Where FI is the financial inclusion index for each year; $\lambda \mathrm{j}$ is the eigenvalue for the $j-t h$ principle component; $\varphi_{j}$ is the factor loadings of each sub - index. Rearranging equation (15) the relative weights of each dimension $W_{i}$; in the final financial inclusion index is calculated. These weights reflect the importance of each dimension in the overall final financial inclusion index. Therefore, higher weights mean that this dimension is highly important and thus policymakers should rely more on this dimension to increase their financial inclusion.

$$
W_{i}=\frac{\sum_{j=1}^{3} \lambda_{i} \varphi_{j k}}{\sum_{j=1}^{3} \lambda_{i}}, \mathrm{k}=1,2,3
$$

\section{Results and Discussions}

This section presents the results of our study. Before applying PCA two tests must be performed, Kaiser-Meyer-Olkin and Bartlett's test of sphericity. These tests ensure that our sample size is adequate, and the selected indicators are inter - correlated. If the value of KMO test is greater than or equal 0.5 and the value of chi-square statistic in Bartlett's test of sphericity is statistically significant; therefore, PCA can be applied (Table 2).

Table 2.

Kaiser-Meyer-Olkin Measure and Bartlett's Test of Sphericity for both traditional and digital datasets

\begin{tabular}{lcc}
\hline \multicolumn{1}{c}{ Measure } & Traditional (2004-2019) & Digital (2004-2019) \\
\hline Kaiser-Meyer-Olkin & 0.759 & 0.713 \\
Bartlett's test of sphericity & $430.015^{*}(45)$ & $183.260^{*}(21)$ \\
\hline
\end{tabular}

Source. Calculated by the author on Stata 14

Notes: *is significant at 5\% level of significance. Figures in parentheses indicate the degree of freedom

In addition, each indicator of each dimension was normalized to have values between zero and one where zero indicates financial exclusion and one indicates financial inclusion.

\subsection{Estimated Results for Traditional Financial Inclusion Index: $\left(F I_{T}\right)$}

First stage PCA results: using PCA method, the eigenvalues of each sub-index and the latent variables are calculated; access $\left(\mathrm{Y}_{\mathrm{a}}\right)$, usage $\left(\mathrm{Y}_{\mathrm{u}}\right)$ and barriers $\left(\mathrm{Y}_{\mathrm{b}}\right)$ that define the three dimensions of our traditional financial inclusion index were estimated. Only principle components with Eigenvalues that are greater than one are considered in our analysis (Kaiser, 1960).

Table 3 shows the estimated principle components and the normalized weights that result from first stage PCA. Column $(2,3,4$, and 5) in the table represents the loading vector for each principle component. The eigenvalues of each PC are represented in the last row of each sub-index (dimension). 
Table 3.

Principle Component Estimates and Normalized Weights

\begin{tabular}{lccccc}
\hline \multicolumn{1}{c}{ Variable } & PC1 & PC2 & PC3 & PC4 & Norm. weights \\
\hline Access - Estimate $Y_{a}$ & & & & & \\
$\quad$ No. of ATMs per 1000 adult & 0.7071 & 0.7071 & - & - & 0.524 \\
$\quad$ No. of Branches per 1000 adult & 0.7071 & -0.7071 & - & - & 0.501 \\
$\quad$ Eigen values & 1.8206 & 0.1791 & - & - & \\
Usage - Estimate $Y_{u}$ & & & & & \\
$\quad$ Debit cards & 0.5267 & -0.02543 & 0.0083 & -0.8493 & 0.2788 \\
$\quad$ Credit cards & 0.5058 & -0.3628 & -0.7155 & 0.3173 & 0.2677 \\
$\quad$ Number of deposits & 0.4605 & 0.8486 & 0.0105 & 0.2601 & 0.2437 \\
$\quad$ Number of borrowers & 0.5048 & 0.3841 & 0.6985 & 0.3313 & 0.2672 \\
$\quad$ Eigen Values & 3.5689 & 0.3365 & 0.0809 & 0.0135 & \\
Barriers - Estimate $Y_{b}$ & & & & & \\
$\quad$ No. of ATMs per 1000 km2 & 0.5166 & 0.1275 & -0.2068 & -0.8211 & 0.2697 \\
$\quad$ No. of Branches per 1000 km2 & 0.4795 & 0.7564 & 0.2751 & 0.3498 & 0.2503 \\
$\quad$ Rural Borrowings & 0.4934 & -0.5756 & 0.6495 & 0.0575 & 0.2576 \\
$\quad$ Rural Savings & 0.5097 & -0.2834 & -0.678 & 0.4474 & 0.2661 \\
$\quad$ Eigen Values & 3.6687 & 0.2689 & 0.0463 & 0.0219 & \\
\hline
\end{tabular}

Source. Calculated by the author on Stata 14

We see that, only the first component of each dimension has an eigenvalue greater than 1; therefore, we will retain only the first component for our analysis. Regarding the weights scheme, we observe that although the weights are not evenly distributed, no indicator is dominant over the other, which represent a desirable condition for index construction. For the access dimension, we found that although the weights are relatively equal, the highest weight is given to the number of ATMs per 1,000 adults. This indicates that the number of ATMs is more important (higher relative weight) than the number of branches in driving this dimension. Actually; in developing countries like Egypt, this result is reasonable; since banks found it very costly to operate in remote locations especially in the rural areas where most of the transaction are on cash basis; therefore; ATMs are providing the basic financial services in these remote areas.

Table 4 shows that for the access dimension, the first principle component explains $91.04 \%$ of the total variation which indicates that both indicators measure the same latent structure

For the usage dimension, we found that although the weights are relatively equal, debit cards $(0.2788)$ and credit cards (0.2677) have the highest consecutive weights. This result indicates that debit cards variable is more important than other indicators defining this dimension. More specifically, this result indicates that in developing countries like Egypt, most of the population demand basic financial products such as debit cards or demand accounts. Moreover, although the first principle component has contributions from all indicators. However, number of deposits and number of borrowers allocates part of their information to the second and the third components by contributing their high loadings to those components, respectively. Thus, owning a credit card, opening a saving account or having a loan represent wider field of financial inclusion in Egypt. Simply, people who have loan or own a credit card means that they already have used another basic financial product such as opening a bank account or even a payroll account. This result is not surprising, since according to the world bank only $33 \%$ of adult population have bank accounts. In addition, table 4 shows that the first component which accounts for $89.22 \%$ of the total information in this dimension, has an even contribution of the four indicators. This proves that the four indicators measure the same latent structure.

For the barriers dimension, we found that although the weights are evenly distributed, number of ATMs per $1000 \mathrm{~km} 2$ (0.2697) and savings in rural areas (0.2661) have the highest consecutive weights. This indicates that Distance is the most important barrier defining this dimension followed by insufficient funds. Once more, this result came with our expectations. 
According to the world bank report, Distance and lack of sufficient funds were cited as the most important barrier for not having a bank account in Egypt.

Table 4.

Cumulative Variance Explained by Components at First Stage PCA

\begin{tabular}{lcc}
\hline Component & Variance Explained & Cumulative Variance \\
\hline Access - Estimate $\mathrm{Y}_{\mathrm{a}}$ & & \\
PC 1 & $91.04 \%$ & $91.04 \%$ \\
PC 2 & $8.9 \%$ & $100 \%$ \\
Usage - Estimate $Y_{u}$ & $89.22 \%$ & $89.22 \%$ \\
PC 1 & $8.41 \%$ & $97.64 \%$ \\
PC 2 & $2.02 \%$ & $99.66 \%$ \\
PC 3 & $0.34 \%$ & $100 \%$ \\
PC 4 & & \\
Barriers - Estimate $Y_{b}$ & $91.72 \%$ & $91.72 \%$ \\
PC 1 & $6.57 \%$ & $98.29 \%$ \\
PC 2 & $1.16 \%$ & $99.45 \%$ \\
PC 3 & $0.55 \%$ & $100 \%$ \\
PC 4 & & \\
\hline
\end{tabular}

Source. Calculated by the author on Stata 14

Finally, we perform the Kaiser-Meyer-Olkin (KMO) test (Table A1 - Appendix) to examine the suitability of the factors and by assigning the weights extracted from PCA to Equations (1 - 3) we get an estimate to each dimension $Y_{a}, Y_{u}, Y_{b}$ and their value as shown in Table A2 Appendix.

Second stage PCA results: In this stage we apply the same steps described in the first stage on the three sub-indices to calculate the weight of each sub-index (dimension) in the overall traditional financial inclusion index. Table A3 - appendix shows that KMO has an overall value of 0.7546 . Therefore, factors used are suitable and consistent with our data. Table 5 presents the estimated principle components and the normalized weights for each sub-index that result from second stage PCA. Column $(2,3$, and 4) in the table represents the loading vector for each principle component. The eigenvalues of each $\mathrm{PC}$ are represented in the last row of each sub-index (dimension).

Table 5.

Principle Component Estimates and Normalized Weights for second stage PCA

\begin{tabular}{lcccc}
\hline \multirow{2}{*}{ Dimensions } & \multicolumn{4}{c}{ Traditional financial inclusion index } \\
\cline { 2 - 5 } & PC1 & PC2 & PC3 & Normalized weight \\
\hline Access & 0.5715 & 0.8187 & 0.0557 & 0.3349 \\
Usage & 0.5796 & -0.4508 & 0.6789 & 0.3397 \\
Barriers & 0.5809 & -0.3556 & -0.7321 & 0.3404 \\
Eigen Values & 2.9117 & 0.0731 & 0.0150 & \\
\hline
\end{tabular}

Source. Calculated by the author on Stata 14

We see that, only the first component of each dimension has an eigenvalue greater than 1 ; therefore, we will retain only the first component for our analysis. Regarding the weights scheme, we found that barriers has the largest weight (0.3404), followed by usage (0.3397) and access (0.3349). This result revealed that barriers is the most important sub-index or dimension in defining the traditional financial inclusion index in Egypt. This result came in line with the literature and our expectations. From an economic point of view, a financial system is inclusive if it minimizes the number of unbanked people who are involuntary excluded from accessing and using the formal financial services. In most developing countries, the formal financial institutions work within a set of overcautious rules that prevent vulnerable 
disadvantaged groups from using their services and thus affect the inclusiveness of the formal financial system. Egypt is not exception; $67 \%$ of the adult population in Egypt depend only on cash in their transactions since they cannot have a bank account (world bank, 2020). This is because either they have no financial identity, lack important official documents as social security number; has insufficient funds to open a bank account; or bank branches are remotely located. Thus, for greater financial inclusion in Egypt the government had to identify the most important barriers facing financial inclusion and consider overcoming these barriers as the main challenge for an inclusive formal financial system.

Moreover, although access is not the most important dimension in defining the traditional FI index; however, it allocates part of its information to the second component. This result indicates that although access is still important dimension in defining overall traditional financial inclusion index, it is seen as necessary but not sufficient condition for using formal financial services. In other words, the availability of formal financial services is not an indication of using or utilizing these services. Table 6 shows the principle component structure, we found that the first component which accounts for $97.06 \%$ of the total variation has an even contribution of all dimensions. This means that the three sub-indices or dimensions have the same latent structure.

Table 6.

Cumulative Variance Explained by Components at Second Stage PCA

\begin{tabular}{lcc} 
Components & $\begin{array}{c}\text { Traditional Financial Inclusion Index } \\
\text { Cumulative Variance }\end{array}$ & $\begin{array}{c}\text { Variance Explained } \\
\text { PC 1 }\end{array}$ \\
PC 2 & 0.9706 & $97.06 \%$ \\
PC 3 & 0.0244 & $99.50 \%$ \\
\hline
\end{tabular}

Source. Calculated by the author on Stata 14

Finally, by calculating the weights for the three dimension we estimate the overall traditional financial inclusion index as shown in Table A4 - Appendix. The result shows that Egypt is classified as one of the countries that has low financial inclusion level in 2019 (FI index $\leq 0.5$ ).

\subsection{Estimated Results for Digital Financial Inclusion Index: ( $\left.F I_{D}\right)$}

First stage PCA results: similar to the first stage steps followed in the traditional financial inclusion index PCA method was used to calculate the eigenvalues of each sub-index and the latent variables; access $\left(\mathrm{Y}_{\mathrm{a}}\right)$, usage $\left(\mathrm{Y}_{\mathrm{u}}\right)$ that define the two dimensions of our digital financial inclusion index were also estimated. Only principle components with Eigenvalues that are greater than one are considered in our analysis (Kaiser, 1960).

Table 7 shows the estimated principle components and the normalized weights that result from first stage PCA. Column (2, 3, 4, and 5) in the table represents the loading vector for each principle component. The eigenvalues of each PC are represented in the last row of each subindex (dimension). 
Table 7.

Principle Component Estimates and Normalized Weights

\begin{tabular}{|c|c|c|c|c|c|}
\hline Variable & PC 1 & PC 2 & PC 3 & PC 4 & $\begin{array}{c}\text { Normalized } \\
\text { weights }\end{array}$ \\
\hline \multicolumn{6}{|l|}{ Access - Estimate $Y_{a}$} \\
\hline No. of Mobile Subscriptions per 100 people & 0.5178 & 0.8413 & 0.1548 & - & 0.3269 \\
\hline$\%$ of Mobile Internet Users & 0.6174 & -0.2422 & -0.7485 & - & 0.3897 \\
\hline $\begin{array}{l}\text { No. of registered Mobile Money Accounts } \\
\text { per } 1,000 \text { people }\end{array}$ & 0.5922 & -0.4832 & 0.6448 & - & 0.3738 \\
\hline Eigen Values & 2.50949 & 0.46104 & 0.02946 & - & - \\
\hline \multicolumn{6}{|l|}{ Usage - Estimate $Y_{u}$} \\
\hline $\begin{array}{l}\% \text { of population makes an online payment } \\
\text { through a mobile device }\end{array}$ & 0.5076 & -0.09056 & -0.6091 & -0.6026 & 0.2633 \\
\hline $\begin{array}{l}\% \text { of population makes an online purchase } \\
\text { or pay a bill }\end{array}$ & 0.4952 & -0.6926 & -0.0032 & 0.5245 & 0.2568 \\
\hline $\begin{array}{l}\text { No. of Mobile Money Transactions per } \\
1,000 \text { Adults }\end{array}$ & 0.5035 & 0.747 & 0.7763 & 0.3719 & 0.2611 \\
\hline Mobile Payments Accounts & 0.4936 & 0.7117 & -0.1622 & 0.4727 & 0.2560 \\
\hline Eigen Values & 3.7173 & 0.1721 & 0.0893 & 0.2121 & - \\
\hline
\end{tabular}

Source. Calculated by the author on Stata 14

We see that, only the first component of each dimension has an eigenvalue greater than 1 ; therefore, we will retain only the first component for our analysis. Regarding the weights scheme, we observe that although the weights are not evenly distributed, no indicator is dominant over the other, which represent a desirable condition for index construction. For the access dimension; we found that the highest weight is given to the \% of Mobile Internet Users (0.3897), followed by No. of registered Mobile Money Accounts per 1,000 people (0.3738) and No. of Mobile Subscriptions per 100 people (0.3629). This result indicates that the \% of Mobile Internet Users is more important (has higher relative weight) than the other two indicators in driving this dimension. Although the percentage of population who own a smart phone had increased rapidly in the last few years to reach $90 \%$ in 2019 , however; only $1.8 \%$ of the population have mobile money account and 3.5\% makes online purchase or pays bills online using their mobile (MCIT, 2020). Therefore, owning a smart phone is not a reliable measure for digital access and could be considered as a necessary but not sufficient condition for accessing digital financial services. In addition, table 8 shows that the first component which accounts for $83.65 \%$ of the total information in this dimension, has an even contribution of the three indicators. This proves that the three indicators measure have the same latent structure.

On the other hand, interpreting the importance of the percentage of mobile internet users in driving the access dimension should be also done with cautious. Recent studies found that people who are from middle - upper socio-economic class use their mobile data for educational services, searching for information, or other services such as checking their account, transfer money, shopping online or paying bills while lower socioeconomic classes use their mobile data only for communication and entertainment purposes such as Facebook and sending voice notes through WhatsApp application (Correa et al., 2018; Bonfadelli,2002; Howard, Rainie, \& Jones, 2001) . In Egypt, the percentage of internet users aged 16 to 64 who use their mobile data in social networking apps, entertainment or video app, and games are $94 \%, 79 \%$, and $44 \%$ while only $17 \%$ use mobile banking apps (MCIT, 2020). This evidence suggests that high $\%$ of mobile internet users does not reflect high digital financial inclusion since the extent of digital inclusion goes beyond access and involves a multidimensional process that include access device as well as digital skills and services used through their mobile data.

For the usage dimension; we found that although the weights are relatively equal, $\%$ of population makes an online payment through a mobile device has the highest weight $(0.2633)$ followed by No. of Mobile Money Transactions per 1,000 Adults (0.2611), \% of population 
makes an online purchase or pay a bill (0.2568) and Mobile Payments Accounts (0.2560). This result indicates that the \% of population makes an online payment using mobile device is the most important indicator in driving the usage dimension. The percent of population who make online payments using their mobile phones in Egypt had increased rapidly from 14\% to 39\% between 2018 - 2020 (MCIT, 2020), which reflects the huge effort exerted by the Egyptian government in the last few years to develop sustainable digital financial services that will facilitate the shift toward a less-cash economy and more electronic payments. These services include besides mobile banking, activation payment gateways and applications such as myFawry, $\mathrm{m}$-wallets and Mobile merchant payments (QR code).

Moreover, although the first principle component has contributions from all indicators. However, number of mobile money transactions and mobile payment accounts allocates part of their information to the second and the third components by contributing their high loadings to those components, respectively. Thus, owning mobile money account or performing any transaction through mobile represent wider field of digital financial inclusion in Egypt. Since mobile payments in Egypt operates on a bank - led model and mobile network operators, therefore; people who have a mobile payment account or perform any transaction using his mobile have already used basic financial services such as having a bank account and digitally aware with the usage of such digital services. In addition, table 8 shows that the first component which accounts for $92.93 \%$ of the total information in this dimension, has an even contribution of the four indicators. This proves that the four indicators measure the same latent structure

Table 8.

Cumulative Variance Explained by Components at First Stage PCA

\begin{tabular}{ccc}
\hline Component & Variance Explained & Cumulative Variance \\
\hline Access - Estimate $Y_{a}$ & & \\
PC 1 & $83.65 \%$ & $83.65 \%$ \\
PC 2 & $15.37 \%$ & $99.02 \%$ \\
PC 3 & $0.98 \%$ & $100 \%$ \\
Usage - Estimate $Y_{u}$ & & \\
PC 1 & $92.93 \%$ & $92.93 \%$ \\
PC 2 & $4.30 \%$ & $97.24 \%$ \\
PC 3 & $2.22 \%$ & $99.47 \%$ \\
PC 4 & $0.53 \%$ & $100 \%$ \\
\hline
\end{tabular}

Source. Calculated by the author on Stata 14

Finally, we perform the Kaiser-Meyer-Olkin (KMO) test (Table A5 - Appendix) to examine the suitability of the factors and by assigning the weights extracted from PCA to Equations (4 - 5) we get an estimate to each dimension $Y_{a}, Y_{u}$, and their value as shown in Table A6 Appendix.

Second stage PCA results: In this stage we apply the same steps described in the first stage on the three sub - indices to calculate the weight of each sub - index (dimension) in the overall digital financial inclusion index. Table A7 - appendix shows that KMO has an overall value of 0.500 Therefore; factors used are suitable and consistent with our data. Table 9 presents the estimated principle components and the normalized weights for each sub - index that result from second stage PCA. Each column in the table represents the loading vector for each principle component. The eigenvalues of each PC are represented in the last row of each sub index (dimension). 
Table 9.

Principle Component Estimates and Normalized Weights for second stage PCA

\begin{tabular}{lccc}
\hline Dimensions & \multicolumn{3}{c}{ Digital financial inclusion index } \\
Access & PC1 & PC2 & Normalized weight \\
\cline { 2 - 4 } Usage & 0.7071 & 0.7071 & 0.5175 \\
Eigen Values & 0.7071 & -0.7071 & 0.5175 \\
\hline
\end{tabular}

Source. Calculated by the author on Stata 14

We see that, only the first component has an eigenvalue greater than 1; therefore; we will retain only the first component for our analysis. Regarding the weights scheme, we found that both access and usage are equally important in explaining digital financial inclusion in Egypt. This result indicates that for Egypt to achieve greater financial inclusion, improving digital technology alone is not enough to ensure greater financial inclusion. Although ICT infrastructure and internet services are cornerstone for the digital use of traditional financial services, however, for greater financial inclusion people must benefit from digital financial services provided. This requires well developed electronic payment gateways, strong and clear regulations, and consumer protection safeguards (Demirguc-kunt et al., 2020). Furthermore, these digital financial services must be directed towards vulnerable disadvantaged groups such as women, poor people in rural and remote areas, and low literacy and skilled people. Finally, table 10 shows that the first principle component analysis which accounts for $93.37 \%$ of the total variation in the data, has an even contribution of the two dimensions. As explained previously, this means that the two dimensions or sub - indices measure the same latent structure which is the degree of digital financial inclusion.

Table 10.

Cumulative Variance Explained by Components at Second Stage PCA

\begin{tabular}{lcc}
\hline \multirow{2}{*}{ Component } & \multicolumn{2}{c}{ Digital Financial Inclusion Index } \\
\cline { 2 - 3 } PC1 & Variance Explained & Cumulative \\
PC2 & $93.37 \%$ & $93.37 \%$ \\
\hline
\end{tabular}

Source. Calculated by the author on Stata 14

Finally; by calculating the weights for the two dimension we estimate the overall digital financial inclusion index as shown in Table A8 - Appendix. The result shows that Egypt is classified as one of the countries that has low digital financial inclusion level (FI index $\leq 0.5$ ). The low level of digital financial inclusion can be attributed to different reasons; limited accessibility and acceptance of digital finance, lack of awareness of digital financial services and products, low digital skills, preference to deal directly with a bank officer, and finally lack of trust in digital financial services (Tilakaratna, 2016 and Central Bank of Egypt, 2018)

\subsection{Estimated Results for Overall Financial Inclusion Index}

In the third stage, we apply PCA in the same steps described above to calculate the weights of both "traditional financial inclusion" and "digital financial inclusion" in the overall final comprehensive FI index for Egypt. Table A9 - appendix shows that KMO has an overall value of 0.5000 . Therefore, factors used are suitable and consistent with our data.

Findings revealed that both "traditional financial index" and "digital financial index" are equally important in explaining overall financial inclusion in Egypt. This result indicates that for an emerging country like Egypt digital finance is seen as a complement rather than a substitute to the traditional financial services. More specifically, digital payments and e-money is provided only through the traditional formal financial institutions to broaden the access and increase the usage of traditional financial services among vulnerable groups and small 
businesses. Thus, digitalization is seen as the only way to increase the pace through which traditional financial services is being delivered.

Using the weights assigned by PCA for the two financial indices, we estimate the overall financial inclusion index. The result shows that Egypt is classified as one of the emerging countries with relatively high financial inclusion level (FI index $>0.5$ ). Although, both traditional and digital financial inclusion are equally important in defining the overall financial inclusion index for Egypt, however, digital finance is playing a significant and positive role in enhancing the financial inclusion in Egypt as evidence by the large increase in the level of inclusiveness after including data on digital payments, mobile money and other digital indicators. Egypt's digital financial inclusion has increased by $11 \%$ and $27 \%$ between $2017 / 2018$ and 2018/2019 respectively which lead to huge improvements in both the access and usages of formal financial services where the traditional financial inclusion has increased by $87 \%$. Accordingly, Egypt's overall financial inclusion level has changed from low (0.41) to relatively high inclusion level $(0.52)$. Table 11 shows that the first principle component analysis which accounts for $97.17 \%$ of the total variation has an even contribution of the two dimensions. As explained previously, this means that the two indices measure the same latent structure.

Table 11.

Cumulative Variance Explained by Principal Components

\begin{tabular}{|c|c|c|c|}
\hline \multicolumn{2}{|c|}{ Traditional Financial Inclusion Index } & \multicolumn{2}{|c|}{ Digital Financial Inclusion Index } \\
\hline $\mathrm{PC} 1$ & 0.9706 & $\mathrm{PC} 1$ & 0.9337 \\
\hline $\mathrm{PC} 2$ & 0.995 & $\mathrm{PC} 2$ & 1 \\
\hline $\mathrm{PC} 3$ & 1 & & \\
\hline \multicolumn{4}{|c|}{ Overall Financial Inclusion Index } \\
\hline & PC1 & & \\
\hline & $\mathrm{PC} 2$ & & \\
\hline
\end{tabular}

Source. Calculated by the author on Stata 14

\section{Conclusion and Policy Recommendations}

The main objective of this paper is to measure Egypt's financial inclusion through constructing a composite multidimensional index. Although few studies took the attempt to measure the inclusiveness of the financial system for Egypt; however, no study did quantify the financial inclusion for Egypt. We thus fill in this gap. We compute two separate indices; traditional (bank) financial index and digital financial index through combining access, usage and barriers indicators for the traditional financial index while for each the digital financial index we combined access and usage indicators, then we build a novel comprehensive financial inclusion index for Egypt.

The results revealed that "Barriers" and "Usage" are key dimensions in determining the degree of traditional financial index. Therefore, for greater financial inclusion, policy makers have to include those people who are involuntary excluded from using formal financial services. Thus, digitalization was seen as the only way to engage those excluded groups in the formal financial services. The evidence presented in this paper proved that the steps taken by the Egyptian government for digitalizing financial services has shifted Egypt from low to relatively high financial inclusion country. More specifically, our comprehensive index shows that the extent of inclusiveness of the formal financial system is determined by increasing traditional and digital "usage" and "access" of formal financial services, as well as by lowering the "Barriers" to include those who were previously excluded from using formal financial services. Thus, digital financial inclusion is seen as a complement rather than a substitute for traditional financial inclusion. 
While we contribute to the literature by being the first who build a comprehensive multidimensional financial inclusion index for Egypt; two limitations dictate an agenda for future research. Creating better comprehensive picture for financial inclusion and how it develops through years requires building complete data sets for individual countries like Egypt that suffers from huge data limitation. Therefore, a comparative study with Egypt as a case study will provide clearer vision concerning the level of financial inclusion since global data sets will be used instead of using country datasets. Secondly, the level of financial inclusion for Egypt might differ severely among Egypt's governorates especially the governorates located in upper Egypt - the poorest governorates. Therefore, similar studies on the level of Egypt's governorates are highly recommended for better picture on the degree of financial inclusion.

Finally, based on our empirical results and for increasing the degree of financial inclusion in Egypt, the government should focus on:

First, opening more bank branches near to rural remote areas will improve the financial inclusion since distance was perceived by the unbanked people as the main important barrier.

Secondly, switching to cashless society will accelerate financial inclusion. This indicates digitalizing all government payments.

Third, strengthen digital financial transaction infrastructure such as e-money and mobile money systems is considered a necessary action for greater financial inclusion.

Fourth, depending on digital platforms provided by Fintech companies in accelerating financial digitalization and e-payment system will increase the inclusiveness of the financial system.

Finally, building trust in digital finance through increasing consumer protection against risks, fraud, and loss of privacy is a must to convince people to use formal financial services through digital channels.

\section{References}

Aduda, J., \& Kalunda, E. (2012). Financial inclusion and financial sector stability with reference to Kenya: A review of literature. Journal of Applied Finance and Banking, 2(6), 95.

Akileng, G., Lawino, G. M., \& Nzibonera, E. (2018). Evaluation of determinants of financial inclusion in Uganda. Journal of Applied Finance and Banking, 8(4), 47-66.

Amidžic, G., Massara, M. A., \& Mialou, A. (2014). Assessing countries' financial inclusion standing-A new composite index. International Monetary Fund.

Anwar, S., Shahzadi, H., \& Nasreen, S. (2017). Determinants of financial development for selected SAARC countries: A panel data analysis. Journal of Applied Environmental and Biological Sciences, 7(7), 109-118.

Awad, M., \& Eid, N. (2018). Financial Inclusion in the MENA Region: A Case Study on Egypt. Journal of Economics and Finance, 9(1).

Beck, T., Demirguc-Kunt, A. and Peria, M.S.M. (2007), "Reaching out: access to and use of banking services across countries", Journal of Financial Economics, Vol. 85 No. 1, pp. 234-266.

Bonfadelli, H. (2002). The Internet and knowledge gaps: A theoretical and empirical investigation. European Journal of communication, 17(1), 65-84.

Bruhn, M., \& Love, I. (2014). The real impact of improved access to finance: Evidence from Mexico. The Journal of Finance, 69(3), 1347-1376.

Burgess, R., \& Pande, R. (2005). Do rural banks matter? Evidence from the Indian social banking experiment. American Economic Review, 95(3), 780-795. 
Cámara, N., \& Tuesta, D. (2014). Measuring financial inclusion: A muldimensional index. BBVA Research Paper, (14/26).

Cámara, N., \& Tuesta, D. (2017). DiGiX: the digitization index (No. 17/03).

Chakravarty, S. R., \& Pal, R. (2013). Financial inclusion in India: An axiomatic approach. Journal of Policy modeling, 35(5), 813-837.

Correa, E., \& Girón, A. (2019). Financial inclusión and financialization: Latin American main trends after the great crisis. Journal of Economic Issues, 53(2), 496-501.

Damodaran, A. (2013). Valuing financial services firms. Journal of Financial Perspectives, $1(1)$.

Demirguc-Kunt, A. and Klapper, L. (2012), "Measuring financial inclusion: the global Findex database (No. 6025)", The World Bank, available at: https://www.bbvaresearch.com/wpcontent/uploads/2014/09/WP14-26_Financial-Inclusion.pdf

Demirguc-Kunt, A., Klapper, L., Singer, D., Ansar, S., \& Hess, J. (2018). The Global Findex Database 2017: Measuring financial inclusion and the fintech revolution. The World Bank.

Demirgüç-Kunt, A., Klapper, L., Singer, D., Ansar, S., \& Hess, J. (2020). The Global Findex Database 2017: Measuring financial inclusion and opportunities to expand access to and use of financial services. The World Bank Economic Review, 34(Supplement_1), S2-S8.

Demirguc-Kunt, A., Klapper,L., Singer, D.,Van Oudheusden, O. 2015. "The Global Findex Database 2014: Measuring Financial Inclusion around the World." Policy Research Working Paper 7255, World Bank Group, Washington, DC

Devlin, J. F. (2005). A detailed study of financial exclusion in the UK. Journal of Consumer Policy, 28(1), 75-108.

Donovan, K. (2012). Mobile money for financial inclusion. Information and Communications for development, 61(1), 61-73.

Goel, S., \& Sharma, R. (2017). Developing a financial inclusion index for India. Procedia computer science, 122, 949-956.

Gomber, P., Koch, J. A., \& Siering, M. (2017). Digital Finance and FinTech: current research and future research directions. Journal of Business Economics, 87(5), 537-580.

GSMA. (2016). State of mobile money in West Africa.

Gupte, R., Venkataramani, B., \& Gupta, D. (2012). Computation of financial inclusion index for India. Procedia-Social and Behavioral Sciences, 37, 133-149.

Honohan, P. (2008). Cross-country variation in household access to financial services. Journal of Banking \& Finance, 32(11), 2493-2500.

Howard, P. E., Rainie, L., \& Jones, S. (2001). Days and nights on the Internet: The impact of a diffusing technology. American Behavioral Scientist, 45(3), 383-404.

Huang, Y., \& Zhang, Y. (2020). Financial inclusion and urban-rural income inequality: Longrun and short-run relationships. Emerging Markets Finance and Trade, 56(2), 457-471.

Hootsuite \& We Are Social (2019), "Digital 2019 Global Digital Overview," retrieved from https://datareportal.com/reports/digital-2019-global-digital-overview

Izquierdo, N. C., \& Tuesta, D. (2015). Factors that matter for financial inclusion: Evidence from Peru. Aestimatio: The IEB International Journal of Finance, (10), 10-31. 
Kaiser, H. F. (1960). The application of electronic computers to factor analysis. Educational and psychological measurement, 20(1), 141-151.

Kelly, S. E., \& Rhyne, E. (2015). By the numbers: Benchmarking progress toward financial inclusion. Center for Financial Inclusion. Accion.

Kempson, E. and Whyley, C. (1999), Kept Out or Opted Out. Understanding and Combating Financial Exclusion, The Policy Press

Kempson, E., Atkinson, A., \& Pilley, O. (2004). Policy level response to financial exclusion in developed economies: Lessons for developing countries. Bristol: Report of Personal Finance Research Centre, University of Bristol.

Klapper, L., El-Zoghbi, M., \& Hess, J. (2016). Achieving the sustainable development goals. The role of financial inclusion. Available online: http://www. ccgap. org. Accessed, 23(5), 2016.

Lenka, S. K., \& Bairwa, A. K. (2016). Does financial inclusion affect monetary policy in SAARC countries?. Cogent Economics \& Finance, 4(1), 1127011.

Lyman, T., \& Lauer, K. (2015). What Is Digital Financial Inclusion and Why Does It Matter?. CGAP Blog, March, 10.

Manyika, J., Lund, S., Singer, M., White, O., \& Berry, C. (2016). Digital finance for all: Powering inclusive growth in emerging economies. McKinsey Global Institute, 1-15.

Mialou, A., Amidzic, G., \& Massara, A. (2017). Assessing countries' financial inclusion standing-A new composite index. Journal of Banking and Financial Economics, (2 (8)).

Nguyen, T. T. H. (2020). Measuring financial inclusion: a composite FI index for the developing countries. Journal of Economics and Development.

Ozili, P. K. (2018). Impact of digital finance on financial inclusion and stability. Borsa Istanbul Review, 18(4), 329-340.

Park, C.Y. and Mercado, R. (2015), Financial Inclusion, Poverty, and Income Inequality in Developing Asia (No. 426), Asian Development Bank, Metro Manila.

Park, C.Y. and Mercado, R. (2018), "Financial inclusion: new measurement and cross-country impact assessment”, ADB Economics Working Paper Series (No. 539 - March 2018), Asian Development Bank, Manila, pp. 1-27.

Prastowo, P., \& Putriani, D. (2019). Income inequality and regional index of financial inclusion for Islamic bank in Indonesia. Al-Iqtishad: Jurnal Ilmu Ekonomi Syariah, 11(1), 135-152.

Sahay R, ihák M, N'Diaye P, Barajas A, Ayala Pena D, Bi R, Gao Y, Kyobe A, Nguyen L, Saborowski C, Svirydzenka K and Yousefi R (2015a) 'Rethinking financial deepening: stability and growth in emerging markets', IMF Staff Discussion Notes, No. 15/8, Washington DC, USA.

Sahay R, ihák M, N'Diaye P, Barajas A, Ayala Pena D, Bi R, Gao Y, Kyobe A, Nguyen - 102 - M J R Garcia C ( C ( L, Saborowski C, Svirydzenka K and Yousefi R (2015b) 'Financial inclusion: can it meet multiple macroeconomic goals?', IMF Staff Discussion Notes, SDN/15/17, Washington DC, USA

Sahay, M. R., von Allmen, M. U. E., Lahreche, M. A., Khera, P., Ogawa, M. S., Bazarbash, M., \& Beaton, M. K. (2020). The promise of fintech: Financial inclusion in the post COVID19 era. International Monetary Fund.

Sarma, M. (2008). Financial inclusion and development: A cross country analysis. 
Sarma, M. (2016). Measuring financial inclusion using multidimensional data. World Economics, 17(1), 15-40.

Sethi, D., \& Sethy, S. K. (2019). Financial inclusion matters for economic growth in India. International Journal of Social Economics.

Sinclair, S. P. (2001). Financial exclusion: An introductory survey. CRSIS, Edinburgh College of Art/Heriot Watt University.

Soejachmoen, M. P. (2016). Financial Inclusion in Indonesia-What We Can do More.

Sun, T. (2018). Balancing Innovation and Risks in Digital Financial Inclusion-Experiences of Ant Financial Services Group. In Handbook of Blockchain, Digital Finance, and Inclusion, Volume 2 (pp. 37-43). Academic Press.

Tilakaratna, G. (2016). Financial inclusion in Sri Lanka: Current status and issues. In Financial Inclusion in Asia (pp. 187-208). Palgrave Macmillan, London.

United Nations. (2016). Digital financial inclusion. international telecommunication union (itu), issue brief series, inter-agency task force on financing for development, July. United Nations. Available at: http://www.un.org/esa/ffd/wp-content/uploads/2016/01/DigitalFinancial-Inclusion_ITU_IATF-Issue-Brief.pdf

World Bank (2018), "Understanding/ poverty/ topics/ financial inclusion", available at: https://www. worldbank.org/en/topic/financialinclusion/overview.

world Bank. (2014). Digital finance: Empowering the poor via new technologies, April 10. Available at: http:/www.worldbank.org/en/news/feature/2014/04/10/digital-financeempowering-poor-new-technologies

Yorulmaz, R. (2013). Construction of a regional financial inclusion index in Turkey. BDDK Bankacllıv ve Finansal Piyasalar Dergisi, 7(1), 79-101.

www.mcit.gov.eg

http://www.cbe.org.eg

https://data.imf.org/FAS.

http://www.worldbank.org/globalfindex. 


\section{Appendix}

Table A1 - KMO test for traditional data variables (First Stage)

\begin{tabular}{ll}
\hline Variable & KMO \\
Access Dimension & Overall (0.5000) \\
Number of ATMs & 0.5000 \\
Number of Branches & 0.5000 \\
Usage Dimension & Overall (0.6553) \\
Number of Credit cards & 0.7398 \\
Number of Debit cards & 0.5905 \\
Number of deposits & 0.5888 \\
Number of borrowers & 0.7256 \\
Barrier Dimension & Overall (0.7670) \\
Number of ATMsKm2 & 0.7153 \\
Number of btranchesKm2 & 0.7339 \\
Borrowed rural & 0.8310 \\
Saved rural & 0.8009 \\
\hline
\end{tabular}

Table A2 - Traditional Financial Inclusion Index by dimension

\begin{tabular}{lcccc}
\hline & Access & Usage & Barriers & FI Index 2019 \\
\hline Traditional Index & 0.51 & 0.17 & 0.22 & 0.41 \\
Table A3 - KMO test for traditional data variables (Second Stage) & & \\
\hline Variable & KMO & \\
\hline Access Dimension & 0.9267 & \\
Usage Dimension & 0.7060 & \\
Barrier Dimension & 0.6807 & \\
Overall & 0.7546 & \\
\hline
\end{tabular}

Table A4 - Traditional financial inclusion index

\begin{tabular}{lccc}
\hline Year & 2018 & 2019 & $\%$ change \\
\hline Traditional financial inclusion index & 0.22 & 0.41 & $86 \%$ \\
\hline
\end{tabular}

Table A5 - KMO test for Digital data variables (First Stage)

\begin{tabular}{lc}
\hline Variable & KMO \\
\hline Access Dimension & Overall (0.5445) \\
Mobile cellular subscriptions (per 100 people) & 0.5949 \\
\% of Mobile Internet Users & 0.5251 \\
Number of registered mobile money accounts per 1,000 adults & 0.5364 \\
Usage Dimension & Overall (0.6627) \\
Mobile payments accounts & 0.6349 \\
Number of mobile money transactions per 1,000 adults & 0.7168 \\
Makes online purchases pr pay an online bill & 0.6317 \\
made an online purchase via a mobile & 0.6715 \\
\hline
\end{tabular}

Table A6 - Digital Financial Inclusion Index by dimension

\begin{tabular}{lccc}
\hline & Access & Usage & FI Index 2019 \\
\hline Digital index & 0.11 & 0.14 & 0.31 \\
\hline
\end{tabular}

Table A7 - KMO test for digital data variables (Second Stage)

\begin{tabular}{|c|c|}
\hline Variable & KMO \\
\hline & 0.5000 \\
\hline Usage Dimension & 0.5000 \\
\hline Overall & 0.5000 \\
\hline
\end{tabular}


INTL. J. APPL. Res. MANAGE. \& ECON., 4 (2):13-34, 2021

Table A8 - Digital financial inclusion index

\begin{tabular}{lccc} 
& $\mathbf{2 0 1 8}$ & $\mathbf{2 0 1 9}$ & \% change \\
Digital Index & 0.24 & 0.31 & $29 \%$ \\
\hline
\end{tabular}

Table A9 - KMO test for overall financial Inclusion Index

\begin{tabular}{ll}
\hline Variable & KMO \\
\hline Traditional financial inclusion index & 0.5000 \\
Digital financial inclusion index & 0.5000 \\
& \\
Overall & 0.5000 \\
\hline
\end{tabular}

